\title{
EL DELITO DE DESAPARICIÓN FORZADA DE PERSONAS EN AMÉRICA LATINA
}

THE CRIME OF FORCED DISAPPEARANCE OF PEOPLE IN LATIN-AMERICA

\section{Isaac Marcelo Basaure Miranda*}

Resumen: El presente trabajo tiene como objetivo determinar el origen del delito de desaparición forzada de personas en América Latina. La metodología que se empleó para llevar a cabo la investigación, consistió en el análisis normativo, histórico y jurisprudencial que a nivel internacional existe en el tema objeto de estudio, utilizando el método teórico analítico. La estructura del artículo inicia con un repaso por la evolución histórica que dicha conducta penal ha tenido en la región. Luego se examinan los precedentes más relevantes de la Corte Interamericana de Derechos Humanos en la materia, a los fines de identificar sus principales estándares interpretativos; como así también su recepción en la Convención Interamericana sobre Desaparición Forzada de Personas, y en los principales tratados y declaraciones internacionales sobre Derechos Humanos. El ensayo concluye con un estudio del impacto reciente de las sentencias de la Corte Interamericana de Derechos Humanos sobre Desaparición Forzada de Personas. Finalmente, se arriba a la conclusión de que el citado delito comenzó a practicarse en Guatemala, en el año 1966, para, a partir de allí, expandirse hacia el resto de América Latina.

Palabras clave: Desaparición forzada de personas, derechos humanos, Corte Interamericana de Derechos Humanos, Convención Interamericana sobre Desaparición Forzada de Personas, Organización de los Estados Americanos

\footnotetext{
* Abogado por la Universidad Nacional de Lomas de Zamora (Buenos Aires, Argentina). Diplomado en Derechos Económicos, Sociales y Culturales por la Secretaría de Derechos Humanos y Pluralismo Cultural de la Nación en conjunto con la Universidad Nacional de la Patagonia San Juan Bosco (Argentina). isaacbasaure@gmail.com
} 
Abstract: The objective of this paper is to determine the origin of the crime of forced disappearance of people in Latin America. The methodology used to carry out the research consisted in the normative, historical and jurisprudential analysis that exists internationally in the subject under study, using the analytical theoretical method. The structure of the article begins with a review of the historical evolution that said criminal behavior has had in the region. Then the most relevant precedents of the Inter-American Court of Human Rights in the matter are examined, in order to identify their main interpretative standards; as well as its reception in the Inter-American Convention on Forced Disappearance of Persons, and in the main international treaties and declarations on Human Rights. The essay concludes with a study of the recent impact of the judgments of the InterAmerican Court of Human Rights on the Forced Disappearance of Persons. Finally, we conclude that the aforementioned crime began to be practiced in Guatemala, in 1966, and, from there, to expand to the rest of Latin America.

Keywords: Forced Disappearance of Persons, Human Rights, InterAmerican Court of Human Rights, Inter-American Convention on Forced Disappearance of Persons, Organization of American States

Sumario. I. Introducción. II. Origen y concepto de la desaparición forzada de personas. III. Estándares interpretativos de la cidh en materia de desaparición forzada de personas. IV. Impacto reciente de las sentencias de la cidh sobre desaparición forzada de personas. V. Conclusión. Referencias.

\section{INTRODUCCIÓN}

«Frente al desaparecido, en tanto esté como tal, es una incógnita. Si el hombre apareciera, bueno, tendrá un tratamiento X, y si la desaparición se convirtiera en certeza de su fallecimiento, tiene un tratamiento Z; pero mientras sea desaparecido no puede tener ningún tratamiento especial; es una incógnita, es un desaparecido, no tiene entidad, no está ni muerto ni vivo, está desaparecido» (Videla, 2013).

La cita pertenece al presidente de facto de la República Argentina, Jorge Rafael Videla, quien gobernó de 1976 a 1981. Durante la segunda mitad del siglo XX imperó en la mayoría de los países de América Latina un profundo desprecio y negación a los derechos humanos. En nuestra región, entre 1950 y 1990, se sucedieron una serie de dictaduras militares, y cívicomilitares, que descollaron por la censura y la represión, por la supresión de los derechos y garantías fundamentales del hombre, por la restricción de 
libertades individuales; por la persecución inclemente a opositores políticos e ideológicos, por fusilamientos clandestinos, por detenciones ilegales, por fraudes electorales, por la desaparición forzosa de personas, y demás violaciones a los derechos humanos. Sin embargo, el objeto del presente trabajo sólo se centra en el delito de desaparición forzada de personas (en adelante DFP).

En una primera aproximación al tema cabe decir preliminarmente que la DFP es la práctica ejecutada, ya sea de forma directa o indirecta, por un aparato estatal, consistente en el arresto, detención o traslado de una persona, a la que se la priva de su libertad; negándose a dar información sobre ella, con el fin de que no se conozca su paradero ni su situación, a los efectos de despojarla de la protección del ordenamiento jurídico vigente, obstaculizando, así, el accionar de la justicia. En otras palabras, la DFP es la invisibilización de la persona por parte del Estado, para que ésta no pueda ser objeto de la tutela jurídica correspondiente.

Autores como Molina Theissen (1996, pp. 65-129), y Citroni (2003, pp. 373-408), coinciden en afirmar que dicha práctica comenzó a desarrollarse, al menos en el ámbito latinoamericano, en Guatemala, entre 1963 y 1966, durante la dictadura del coronel Alfredo Enrique Peralta Azurdia, quien al asumir el poder derogó la Constitución Política de la República de Guatemala de 1956, iniciando la desaparición de opositores. Y es que la DFP, es una consecuencia del gran anhelo perseguido por las dictaduras de América: silenciar al adversario. No obstante, es preciso aclarar que la DFP no es privativa de Gobiernos dictatoriales, ya que tanto en Colombia ${ }^{1}$, Perú $^{2}$, Argentina ${ }^{3}$ y México ${ }^{4}$, por ejemplo, se han cometido DFP durante los Gobiernos de Ernesto Samper, Alberto Fujimori, Cristina Fernández de Kirchner y Luis Echeverría Álvarez, respectivamente; todos ellos presidentes democráticamente electos.

Pero más allá de ello, lo cierto es que la comisión de este delito tuvo su auge durante las dictaduras militares latinoamericanas del siglo XX. En este sentido, a modo introductorio, resulta pertinente realizar una breve cronología histórica. Comencemos con los años cincuenta. En Nicaragua, en el año 1950 el dictador Anastasio Somoza García ascendía a la primera magistratura; en Cuba el 10 de marzo de 1952, el general Fulgencio Batista, tras perpetrar un golpe de estado, se proclamaba presidente; en Venezuela el 2 de diciembre de 1952, una junta de Gobierno designaba al general Marcos

\footnotetext{
${ }^{1}$ CIDH, Vereda La Esperanza vs. Colombia, sentencia de 31-VIII-2017.

${ }^{2}$ CIDH, Comunidad Campesina de Santa Bárbara vs. Perú, sentencia de 1-IX-2015.

${ }^{3}$ CIDH, Torres Millacura y otros vs. Argentina, sentencia de 1-VIII-2011.

${ }^{4}$ CIDH, Radilla Pacheco vs. México, sentencia de 23-XI-2009.
} 
Pérez Jiménez como nuevo presidente; En Colombia el 13 de junio de 1953, el general Gustavo Rojas Pinilla se consagraba presidente, tras llevar a cabo un golpe de estado; en Guatemala el 1 de septiembre de 1954, el coronel Carlos Castillo Armas, mediante golpe de estado, asumía el Poder Ejecutivo; en Paraguay el 15 de agosto de 1954 el general Juan Alfredo Stroessner iniciaba una de las dictaduras más extensas de Latinoamérica (terminaría en 1989), al derrocar por golpe de estado al presidente constitucionalmente electo; y en Haití el 22 de octubre de 1957 asumía el mandato presidencial François Duvalier, quien en 1964 se autoproclamaría presidente vitalicio, iniciando así, una dictadura que continuaría su hijo, Jean-Claude Duvalier, hasta su derrocamiento en 1986.

Los mencionados gobiernos fueron los antecedentes inmediatos de las nuevas dictaduras que se implantaron más tarde en los sesenta. Son ejemplos el golpe de estado que sufrió la democracia brasileña, efectuado por las Fuerzas Armadas en 1964, el cual derrocó al presidente João Goulart e instauró en su lugar al mariscal Humberto de Alencar Castelo Branco. Esta dictadura se prolongaría hasta 1985. En Bolivia, el general René Barrientos fue elegido presidente por una junta militar en 1964, tras cometer ésta un golpe de estado, inaugurando así una sucesión de dictaduras que duraría hasta 1982. Por su parte, en Perú el general Juan Velasco Alvarado en 1968 se alzaba con la Presidencia valiéndose de un golpe de estado.

En los años setenta se produjeron decisivas transformaciones políticas en el continente que contribuyeron a consolidar gobiernos de facto. $\mathrm{La}$ primera de ellas ocurrió en Bolivia, con el golpe de estado de 1971, cometido por el militar Hugo Bánzer Suárez; la segunda, sobrevendría con el golpe de estado padecido por la República del Ecuador, ocurrido en el año 1972, llevado a cabo por el general Guillermo Rodríguez Lara contra el presidente José María Velasco Ibarra. La tercera circunstancia que modificó el plano geopolítico, ya en el Cono Sur, fue el autogolpe de estado que realizó Juan María Bordaberry, presidente democráticamente electo de Uruguay, que con el apoyo de las Fuerzas Armadas, en 1973 lideró un golpe de estado que suprimió el Congreso Nacional instalando un Gobierno dictatorial. Meses más tarde en ese mismo año, en Chile el general Augusto Pinochet hacía lo propio al encabezar el golpe de estado que derrocaría al presidente Salvador Allende. Finalmente, en Argentina la presidenta María Estela Martínez de Perón fue derrocada en 1976 por una junta militar que designaría a Jorge Rafael Videla como presidente de facto.

Mientras la escalada despótica se expandía en América Latina, paralelamente, el derecho internacional experimentaba una evolución a nivel continental, con la aprobación de la Convención Americana sobre Derechos 
Humanos (en adelante CADH), suscrita inicialmente por doce estados ${ }^{5}$ el 22 de noviembre de 1969 en San José de Costa Rica, tratado que entró en vigor el 18 julio de 1978. El texto declaraba que su propósito era el de «consolidar en este Continente, dentro del cuadro de las instituciones democráticas, un régimen de libertad personal y de justicia social, fundado en el respeto de los derechos esenciales del hombre». La Convención adquiere una relevancia sustancial en el tratamiento de la DFP, ya que su art. 33 dispuso la creación de dos órganos fundamentales para el control y efectivo cumplimiento de los derechos humanos: la Comisión Interamericana de Derechos Humanos (en adelante simplemente "la Comisión"), y la Corte (en adelante CIDH). Así las cosas, desde sus inicios la Comisión comenzó a manifestar sus primeras inquietudes acerca de la sistemática violación a los derechos humanos por parte de las dictaduras imperantes en aquella época, especialmente sobre personas desaparecidas:

«La Comisión se ha informado ampliamente acerca de actos que violan el derecho de libertad sindical en algunos países americanos. Estos hechos suelen configurarse de distinta manera; unas veces suprimiendo a los dirigentes sindicales determinado fuero para la adecuada realización de sus gestiones (...) y otras aplicando simplemente el encarcelamiento, el terror o hasta la desaparición de dirigentes sindicales» (Comisión, Informe Anual de 1972).

En el Informe Anual de 1974, la Comisión ya comienza a hablar de «desaparecidos», al resolver tomar por verdaderos los hechos denunciados en una comunicación enviada por ciudadanos bolivianos, la cual versaba sobre la detención ilegal en la ciudad de Achocalla, de las señoras Amalia Rada, Aída Pechazas (o Pedrazas) y Elsa Burgoa de Zapata, que habrían denunciado a la Cruz Roja, la práctica de torturas y desaparecidos en Bolivia, después de que una comisión investigadora se retiró de la localidad. Pero la preocupación más evidente de la Comisión en la materia surge en 1976:

«Son muchos ya los casos que se registran de personas "desaparecidas". Es decir de personas que según testimonios y otros elementos de prueba han sido detenidas por autoridades militares o policiales pero cuya detención se niega y cuyo paradero se ignora» (Comisión, Informe Anual de 1976).

Al año siguiente la Comisión reitera su desasosiego: «Una situación que ha venido preocupando hondamente a la Comisión y de la que precisamente dio cuenta en su anterior informe, es la que afecta a los llamados "desaparecidos"»; agregando que: "son muchos los casos, en

${ }^{5}$ En concreto, Chile, Colombia, Costa Rica, Ecuador, El Salvador, Guatemala, Honduras, Nicaragua, Panamá, Paraguay, Uruguay y Venezuela. 
diferentes países, en que el Gobierno niega sistemáticamente la detención de personas» (Informe Anual de 1977). Por su parte, la ONU exteriorizaba su pedido a los gobiernos de que «en el caso de informes de desapariciones forzosas o involuntarias, dediquen los recursos adecuados a la búsqueda de esas personas, y hagan investigaciones rápidas e imparciales» (ONU, 1978, Resolución 33/173).

Los informes de la Comisión constituyen valiosos documentos para identificar en qué periodo histórico la DFP se convirtió en América Latina en un flagelo inocultable; la conclusión es evidente: la década de los setenta. El Informe de la Comisión Presidencial Asesora para la Calificación de Detenidos y Desaparecidos, Ejecutados Políticos y Víctimas de Prisión Política y Tortura de Chile de 2011 (mejor conocido como Informe Valech II), creado por mandato de la Ley 20.405 de 2009, estima que la dictadura de Pinochet arrojó un saldo de más de 40 mil casos que incluyen desaparecidos, ejecutados políticos, víctimas de prisión política y tortura. Por otro lado, en Argentina el informe elaborado por el Registro Unificado de Víctimas del Terrorismo de Estado (Ministerio de Justicia y Derechos Humanos de la Nación Argentina, 2016) sostiene que durante la última dictadura (1976-1983), existen al menos 8.753 casos de desaparición comprobados. Sin embargo, organismos de derechos humanos, como las Abuelas de Plaza de Mayo (2016), sostienen que la cifra es mucho mayor, es decir, alrededor de 30 mil desaparecidos, dado que parten de una estimación de casos no denunciados ${ }^{6}$.

Las cifras demuestran, entonces, que Argentina y Chile fueron los gobiernos que más contribuyeron a materializar la desaparición de personas en el continente. Muchos familiares de las víctimas del terrorismo de estado recurrieron a la figura del papa Juan Pablo II, quien intervino a favor de los desaparecidos, declarando:

«Que se acelere la anunciada definición de las situaciones de los detenidos y que se mantenga un compromiso riguroso para tutelar, en todas las circunstancias requeridas por la observación de las leyes, el respeto de la persona física y moral, incluso de los culpables o acusados de violaciones de la ley» (Discurso, 28-X-1979).

La exhortación papal fue un hecho trascendental para visibilizar la problemática de los desaparecidos en Latinoamérica. Por ejemplo, obligó al dictador Videla a pronunciarse por primera vez, en plena conferencia de prensa, sobre las miles de personas desaparecidas:

\footnotetext{
${ }^{6}$ La Provincia de Buenos Aires ha contribuido a zanjar la cuestión del número de desaparecidos, al ordenar mediante Ley 14.910 que se incorpore en todas las publicaciones y actos de gobierno de la provincia, el número 30.000 junto a la expresión «desaparecidos».
} 
Esa advertencia del Papa, en su condición de pastor, de instar a la dignidad del hombre, no está ajena a nuestro sentir. Porque, justamente, para defender la libertad y la dignidad del hombre, la Argentina tuvo que enfrentar éste tremendo problema de una guerra en la que pagó precio de sangre (en Pigna, 18-V-2013) ${ }^{7}$.

En atención al contexto socio-político desarrollado hasta aquí, en lo relativo a la desaparición forzada la OEA declaró «que la práctica de la desaparición forzada de personas en América es una afrenta a la conciencia del Hemisferio y constituye un crimen de lesa humanidad» (Resolución 666 de 1983); asimismo, exhortaba a los Estados en los que hubiese ocurrido este tipo de desapariciones, a esclarecer su situación, además de informar a sus familiares sobre la suerte corrida por la víctima. Lo resuelto por la OEA supuso el primer reconocimiento declarativo, a nivel interamericano, de que la DFP perpetrada por aparatos estatales implicaba un delito contra los derechos humanos.

La CIDH, en Velásquez Rodríguez vs. Honduras (1988), tuvo la ocasión de desarrollar por primera vez la cuestión de los desaparecidos. En ella, condenó a Honduras a reparar económicamente a la esposa e hijos de Manfredo Velásquez, por su desaparición forzada, cometida por la acción directa del Estado. El próximo hito normativo vinculado con el tema fue la Declaración sobre la protección de todas las personas contra las desapariciones forzadas, adoptada por la Asamblea General de la ONU en 1992, a la que le sobrevino la Convención Interamericana sobre Desaparición Forzada de Personas, adoptada por la OEA el 9 de junio de 1994 (en adelante CIDFP); el Estatuto de Roma de la Corte Penal Internacional, aprobado el 17 de julio de 1998; y, finalmente, la Convención Internacional para la protección de todas las personas contra las desapariciones forzadas, refrendada por la ONU el 20 de diciembre de 2006 (en adelante la Convención de la ONU).

Expuesto a modo introductorio el contex to histórico en el que emergió el término de DFP en América Latina, se procederá, a continuación, a examinar con mayor profundidad el origen de la conducta penal objeto de análisis, su concepto y caracteres, las sentencias más relevantes de la Corte vinculadas a la problemática en estudio, así como también su tipificación en los tratados internacionales; para finalmente concluir con un breve análisis acerca del impacto reciente de las sentencias de la CIDH en la materia.

${ }^{7}$ La respuesta remata con la cita escrita al inicio del presente trabajo. 


\section{ORIGEN Y CONCEPTO DE LA DESAPARICIÓN FORZADA DE PERSONAS}

La doctrina coincide en afirmar que el origen moderno de la DFP se halla en las Directivas para la persecución de las infracciones cometidas contra el Reich o las Fuerzas de Ocupación en los Territorios Ocupados, conocidas, luego de los Juicios de Núremberg, bajo el nombre de «Decreto Noche y niebla» (Nacht-und-Nebel-Erlass en su idioma original) de diciembre de 1941, redactado por el mariscal Wilhelm Keitiel y ordenado por el líder nazi, Adolf Hitler, durante el comienzo de la Segunda Guerra Mundial (Ambos \& Böhm, 2009). Se cree que Hitler nombró al decreto «Noche y niebla», en homenaje a la ópera de Richard Wagner El oro del Rin (1869) en la que el personaje Alberich — un enano malvado - canta, luego de colocarse un yelmo mágico que lo vuelve invisible e impune: «Noche y niebla. ¡Ya no hay nadie!» (Huhle, 2014, IV, 251-278). La singular denominación implicaba cierta alegoría macabra, ya que el decreto contenía disposiciones y protocolos de actuación tendientes a secuestrar y suprimir, en secreto, y durante la noche, a todos aquellos sospechosos de resistencia en los territorios de Europa Occidental ocupados por el Tercer Reich. De modo que un opositor arrestado en el extranjero era inmediatamente trasladado a Alemania, donde desaparecía sin dejar rastros. En el marco de dicha metodología criminal, la evaporación de la persona impedía conocer su paradero o situación, lo cual acrecentaba la angustia de sus familiares y generaba pánico en la población. El fin de la ley era, entonces, crear una intimidación efectiva que paralizase toda acción opositora.

Como afirma Boronat (2013, pp. 226-246), «el efecto intimidatorio de estas medidas descansa en a) la desaparición sin rastro de los inculpados, b) que no esté permitido bajo ningún concepto dar información sobre su paradero o destino». Y es que la desaparición, desde el paradigma represivo, era un estado perfecto para ocultar cualquier indicio de delito, máxime cuando esta conducta ni siquiera se hallaba tipificada por los tratados internacionales. ¿Qué ley se podía aplicar, en aquel entonces, a una persona que se desvanecía de un día para otro sin volver a aparecer jamás? ¿A dónde se la buscaba? ¿A quién se reclamaba? Era una medida orientada a entorpecer la justicia, por lo que muchas de las dictaduras de América Latina la emplearon.

En la misma línea, la Comisión sostuvo que «la "desaparición" parece ser un expediente cómodo para evitar la aplicación de las disposiciones legales establecidas en defensa de la libertad individual, de la integridad física, de la dignidad y de la vida misma del hombre» (Informe Anual, 1976). 
En el ámbito latinoamericano, la DFP se originó de manera sistemática en Guatemala durante la década del sesenta. En marzo de 1966 se comete la primera DFP a gran escala. En un clima post-electoral en el que había resultado electo el presidente Julio César Méndez Montenegro, las fuerzas de seguridad detuvieron, al menos a 28 personas opositoras al régimen guatemalteco que acababa de ser derrotado en las urnas. «Los capturados nunca fueron arrestados ni sometidos a juicio; tampoco liberados y sus cuerpos nunca aparecieron. Simplemente fueron "desaparecidos" (Ball, Kobrak \& Spirer, 1999). A partir de allí, se acrecentarían los conflictos armados internos, dando inicio a una guerra civil entre los diferentes Gobiernos que se sucedieron, contra grupos de guerrilla, principalmente representados por la Unidad Revolucionaria Nacional Guatemalteca (URNG). La disputa se extendería hasta el Acuerdo de Paz de 1996. La tragedia del enfrentamiento armado, según la Comisión para el Esclarecimiento Histórico (CEH), causó la desaparición forzada de 6.159 personas (Simon, 2003).

Entre 1960 y 1980, estas desapariciones se propagarían luego a otros países del continente, como Argentina, Bolivia, Brasil, Chile, Colombia, El Salvador, Haití, Honduras, Perú, México, y Uruguay. Así, sólo por citar algunos ejemplos, en Brasil, aparece con la implantación de regímenes dictatoriales, a partir del golpe de estado de 1964 perpetrado por las Fuerzas Armadas, quienes nombraron presidente a Humberto de Alencar Castelo Branco. En junio del mismo año, se creó el Servicio de Inteligencia Nacional (SIN), organismo encargado de recolectar información sobre los opositores, para posteriormente hacerlos desaparecer en establecimientos clandestinos de detención. La Comisión Nacional de la Verdad creada por el gobierno de Dilma Rousseff en 2014, comprobó que las dictaduras que se sucedieron entre 1964 y 1985 fueron responsables de la desaparición forzada de al menos 210 personas (cfr. Dallari, 2015, pp. 46-54).

En Bolivia, la DFP se patentizó con la dictadura de Hugo Bánzer Suárez (1971-1978). Un informe elaborado por Amnistía Internacional (2016) estima que durante este gobierno 150 personas al menos fueron desaparecidas forzosamente. En Ibsen Cárdenas e Ibsen Peña vs. Bolivia (2010), la Corte condenó a Bolivia a reparar económicamente a los familiares de Rainer Ibsen Cárdenas por su desaparición cometida por agentes estatales. La mentada sentencia sostuvo:

«Los hechos del presente caso se enmarcan en la dictadura militar del entonces Coronel Hugo Bánzer Suárez, iniciada en agosto de 1971. A lo largo de esa época se cometieron numerosas violaciones a los derechos humanos en el marco de una política de represión a grupos y personas que eran identificados por el gobierno como enemigos u opositores del régimen». 
En Chile, la DFP se generalizó, como práctica sistemática, tras el derrocamiento del presidente Allende, y la posterior asunción al poder de Augusto Pinochet, cuya dictadura se prolongó desde 1973 hasta 1990. Las actividades de secuestro y desaparición de opositores eran cumplidas por la Dirección de Inteligencia Nacional (DINA), a cargo del militar Manuel Contreras Sepúlveda. Años más tarde la Corte Suprema de Justicia de Chile, en el caso Miguel Ángel Sandoval Rodríguez (2014) condenó a Contreras, director de la DINA, por la desaparición forzada de un joven sastre, quien fue trasladado a inicios de 1975 al centro clandestino de torturas Villa Grimaldi, donde fue visto por última vez. El fallo del máximo tribunal chileno es relevante, ya que se consideró que la DFP es un delito permanente mientras no aparezca el cuerpo de la víctima. El Informe Valech II (2011) realizado en Chile, concluye que «las víctimas reconocidas en ésta etapa, 30 detenidos desaparecidos y ejecutados políticos y 9.795 víctimas de prisión política y tortura, elevan a más de 40 mil los casos reconocidos por esta Comisión y sus predecesoras». El informe asegura además que entre 1973 y 1990 Chile sufrió una política de Estado en materia de violaciones de derechos humanos.

Finalmente, la última dictadura que se instaló en América Latina durante la década del setenta fue la argentina. El fenómeno de la DFP se cristalizó con la dictadura militar de Jorge Rafael Videla (1976-1981), en el marco del llamado «proceso de reorganización nacional». Los opositores al régimen eran secuestrados y privados de la libertad por agentes estatales que operaban bajo órdenes de los altos mandos de las Fuerzas Armadas, cuya misión era trasladar a los detenidos a centros clandestinos de detención y tortura - entre los que destacó la tristemente célebre Escuela de Mecánica de la Armada (ESMA) - , donde la mayoría de ellos desaparecía. El objetivo del gobierno militar era, pues, el exterminio de los opositores. Ya restaurada la democracia en Argentina, luego de las elecciones presidenciales del año 1983 que proclamaron como ganador al Dr. Raúl Alfonsín, el nuevo Ejecutivo ordenó someter a juicio a las juntas militares que gobernaron durante la dictadura de Videla, sosteniendo que «entre los años 1976 y 1979 aproximadamente, miles de personas fueron privadas ilegalmente de su libertad, torturadas y muertas como resultado de la aplicación de esos procedimientos de lucha inspirados en la totalitaria "doctrina de la seguridad nacional"» (Decreto 158/1983). En cumplimiento de este decreto, la Cámara Nacional de Apelaciones en lo Criminal y Correccional Federal de la Capital Federal sustanció la causa 13/84, sentenciando en 1985 al dictador Videla a la pena de la reclusión perpetua. En la actualidad, el reciente informe del Registro Unificado de Víctimas del Terrorismo de Estado (Ministerio de 
Justicia y Derechos Humanos de la Nación Argentina, 2016) confirma que durante la última dictadura argentina sufrieron DFP unas 8.753 personas.

Vemos, pues, que el delito de DFP tuvo su origen a nivel mundial en Alemania, con el Decreto Noche y Niebla del año 1941 de Hitler. Mientras que en América Latina el primer antecedente relevante surgió en Guatemala, en el año 1966, con el famoso caso de «los 28 desaparecidos», ocurrido durante el gobierno de facto de Enrique Peralta Azurdia.

A los fines de elucidar el concepto de DFP, hemos de examinar las diversas definiciones de los tratados y declaraciones internacionales sobre el tema. El primer instrumento internacional que se ocupó de elaborar una definición del delito de DFP fue la Declaración de la ONU de 1992. En ella, la Asamblea General sostuvo que este delito se consuma cuando se:

«(...) arreste, detenga o traslade contra su voluntad a las personas, o que éstas resulten privadas de su libertad de alguna otra forma por agentes gubernamentales de cualquier sector o nivel, por grupos organizados o por particulares que actúan en nombre del gobierno o con su apoyo directo o indirecto, su autorización o su asentimiento, y que luego se niegan a revelar la suerte o el paradero de esas personas o a reconocer que están privadas de la libertad, sustrayéndolas así a la protección de la ley».

De lo que se extrae que, la primera acción que contribuye a producir el delito de DFP, es la privación de la libertad, ya sea mediante un arresto, detención o traslado. El segundo supuesto que configura la conducta penal, es que el evento ilícito debe ser cometido por el Estado, en cualquiera de sus formas. No es imprescindible que éste actúe de forma oficial, sino que basta que brinde su colaboración o aquiescencia, por acción u omisión, a través del engranaje estatal. El tercer acto que integra la DFP es la negativa categórica de las autoridades estatales a reconocer el delito, evitando informar sobre la ubicación o destino de la víctima, con la intención deliberada de obstaculizar el accionar de la justicia, al no poder darle ésta la protección jurídica adecuada al desaparecido, ya que desconoce cuál es su situación real.

El primer tratado continental específico sobre la materia fue la CIDFP de 1994, que dice:

«Se considera desaparición forzada la privación de la libertad a una o más personas, cualquiera que fuere su forma, cometida por agentes del Estado o por personas o grupos de personas que actúen con la autorización, el apoyo o la aquiescencia del Estado, seguida de la falta de información o de la negativa a reconocer dicha privación de libertad o de informar sobre el paradero de la persona, con lo cual se impide el ejercicio de los recursos legales y de las garantías procesales pertinentes» (art. 2). 
Como se observa, se repiten los mismos criterios establecidos en la Declaración de la ONU de 1992, es decir: a) la privación de la libertad, ya sea legal o ilegal; b) hecha por actuación del Estado en cualquiera de sus formas; y, c) la negativa a dar información sobre la víctima, con el fin de entorpecer la justicia.

También el Estatuto de Roma de 1998 se ocupó de tipificar esta conducta. En primer término, el Estatuto considera a la DFP como un crimen de lesa humanidad, entendiendo por tal aquel acto que se comete «como parte de un ataque generalizado o sistemático contra una población civil y con conocimiento de dicho ataque». El art. 7.i) define que:

«Por "desaparición forzada de personas" se entenderá la aprehensión, la detención o el secuestro de personas por un Estado o una organización política, o con su autorización, apoyo o aquiescencia, seguido de la negativa a admitir tal privación de libertad o dar información sobre la suerte o el paradero de esas personas, con la intención de dejarlas fuera del amparo de la ley por un período prolongado».

El Estatuto de Roma amplía el espectro de la DFP, ya que agrega como sujeto activo del delito a las organizaciones políticas. En consecuencia, la DFP puede ser cometida tanto por el Estado, como por una organización política ajena a éste, abriendo la posibilidad de que pueda ser cometida por particulares. Dicha interpretación podría suscitar conflictos al momento de diferenciar una DFP y un secuestro. La diferencia, a nivel punitivo es sustancial, ya que la primera constituye un crimen de lesa humanidad y, por tanto, es imprescriptible según la Convención sobre Imprescriptibilidad de los Crímenes de Guerra y de los Crímenes de Lesa Humanidad de 1968; en cambio, la segunda conducta penal quedaría circunscripta al ordenamiento jurídico interno de cada país, además de ser prescriptible.

A fin de aportar una solución a dicha problemática, señalamos que toda DFP materialmente supone un secuestro, pero no todo secuestro constituye una DFP. La primera diferencia es subjetiva: la DFP es perpetrada por el Estado, por ejemplo, a través del accionar de un funcionario público, de manera directa o indirecta; mientras que la segunda es llevada a cabo por un particular. Otro criterio distintivo de ambos delitos podría consistir en que la DFP tiene como finalidad la eliminación del opositor ideológico o político, y es cometida por grupos de poder político o militar que llevan adelante una política represiva premeditada, cuya autoría intelectual proviene de una doctrina ideológica impuesta por los altos rangos del gobierno, sea éste cívico o castrense (cfr. Brijalbo \& Londoño, 2004). Mientras que el secuestro es un delito aislado, cometido por particulares, que no se enrola en un plan masivo y sistemático de desapariciones, sino que se tipifica como una conducta penal concreta, carente de conexiones con un 
engranaje estatal despótico que persiga la evaporación del adversario político o ideológico. Otro criterio diferenciador adicional es el carácter pluriofensivo que posee la DFP. El secuestro afecta solamente el bien jurídico tutelado de la libertad personal, mientras que la DFP va más allá, afectando la libertad personal, la integridad personal, el derecho a ser sometido a juicio a cargo de juez competente, $y$, en la mayoría de las ocasiones, viola también el derecho a la vida. Otro factor importante a considerar, que consta en la definición dada por el Estatuto de Roma, es el tiempo: la DFP debe extenderse por un período prolongado de tiempo.

El último tratado internacional que hace referencia directa al tema es la Convención de la ONU de 2006, que dispone en su art. 2:

«A los efectos de la presente Convención, se entenderá por "desaparición forzada" el arresto, la detención, el secuestro o cualquier otra forma de privación de libertad que sean obra de agentes del Estado o por personas o grupos de personas que actúan con la autorización, el apoyo o la aquiescencia del Estado, seguida de la negativa a reconocer dicha privación de libertad o del ocultamiento de la suerte o el paradero de la persona desaparecida, sustrayéndola a la protección de la ley».

Desde el punto de vista conceptual, no introduce ningún elemento novedoso a lo ya establecido por anteriores instrumentos internacionales. Sin embargo, resulta interesante mencionar que no se admiten ningún tipo de excepciones o justificativos para eludir la responsabilidad penal por la comisión de DFP: «En ningún caso podrán invocarse circunstancias excepcionales tales como estado de guerra o amenaza de guerra, inestabilidad política interna o cualquier otra emergencia pública como justificación de la desaparición forzada» (art. 1).

Por lo desarrollado hasta aquí, es posible sostener que la DFP es un delito de lesa humanidad, imprescriptible, consistente en la privación de la libertad de una o más personas, mediante arresto, detención, traslado o cualquier otro medio, perpetrado por agentes estatales, por particulares al servicio de éste, o por organizaciones políticas; quienes proceden a ocultar a la persona, para luego negar o desconocer cualquier información relativa al paradero, ubicación o destino de la víctima, con el fin, claro y deliberado, de sustraerla de la protección jurídica correspondiente.

\section{ESTÁNDARES INTERPRETATIVOS DE LA CIDH EN MATERIA DE DESAPARICIÓN FORZADA DE PERSONAS}

La primera ocasión en que la CIDH tuvo oportunidad de manifestarse sobre este crimen fue en el caso Velásquez Rodríguez vs. Honduras (1988). 
La sentencia estableció la responsabilidad internacional de Honduras por la detención y posterior desaparición de Ángel Manfredo Velásquez Rodríguez, un estudiante de la Universidad Nacional Autónoma de Honduras, quien el 12 de septiembre de 1981 fue secuestrado por un grupo de hombres armados vinculados a las Fuerzas Armadas, en un estacionamiento de vehículos del centro de la ciudad de Tegucigalpa. La $\mathrm{CIDH}$, asegura que éste hecho se produjo en el marco de una serie de desapariciones forzadas que ocurrieron en el Estado hondureño, entre 1981 y 1984, en el transcurso del cual desaparecieron, aproximadamente, 150 personas. En dicha sentencia, la CIDH estableció, como primera fuente aplicable para determinar el delito de DFP, a la CADH. Ello es así, ya que al tiempo de dictarse el fallo (1988) no existía ningún tratado internacional aplicable a los Estados miembros de la CADH que emplease la calificación legal de DFP; en efecto, la CIDFP, no se aprobaría sino hasta 1994. Sin embargo, la $\mathrm{CIDH}$, consideró que tanto: «La doctrina como la práctica internacionales han calificado muchas veces las desapariciones como un delito contra la humanidad». Bajo este argumento, la CIDH estableció que la DFP: «Constituye una violación múltiple y continuada de numerosos derechos reconocidos en la Convención». Aquí tenemos, entonces, el primer criterio interpretativo: la DFP debe ser considerada como un delito pluriofensivo; lo que significa que en ella concurren, simultánea o alternativamente, lesiones a la integridad personal, al derecho a la vida, y a la libertad personal. En la interpretación de la $\mathrm{CIDH}$, el secuestro de la persona, es decir, la privación arbitraria de la libertad, sumado a la negativa a trasladar al detenido ante un juez competente para que pueda controlar la legalidad de su arresto, constituirían la violación a la libertad personal. Mientras que «El aislamiento prolongado y la incomunicación coactiva a los que se ve sometida la víctima», suponen la violación del derecho a la integridad personal. Finalmente, la CIDH constata que la práctica de DFP con frecuencia implica «La ejecución de los detenidos, en secreto y sin fórmula de juicio, seguida del ocultamiento del cadáver con el objeto de borrar toda huella material del crimen y de procurar la impunidad de quienes lo cometieron» (Velásquez Rodríguez vs. Honduras, 1988) constituyendo así una afrenta al derecho a la vida. Sin embargo, ésta última lesión puede o no ocurrir, ya que la propia CIDH utiliza la frase «con frecuencia» no siendo, por lo tanto, un elemento esencial para que se configure el delito. De modo que los derechos contenidos en la $\mathrm{CADH}$, que, eventualmente, pueden resultar lesionados por la comisión del delito de DFP, son, a juicio de la 
CIDH: la obligación de respetar los derechos (art.1) ${ }^{8}$; el derecho a la vida (art. 4); el derecho a la integridad «física, psíquica y moral» (art. 5); y el derecho a la libertad personal (art. 7). En consecuencia, la práctica de la DFP por cualquiera de los Estados miembros de la OEA, supone la ruptura radical de la CADH.

La jurisprudencia de la CIDH, reafirmaría, en los años siguientes a su primer pronunciamiento sobre DFP, el carácter pluriofensivo de ésta. Así, en Godínez Cruz vs. Honduras (1989, § 163) se consolida el estándar interpretativo. En el caso Fairén Garbi y Solís Corrales vs. Honduras (1989, $\S 147)$, se sostiene que:

«El fenómeno de las desapariciones involuntarias constituye una forma compleja de violación de los derechos humanos que debe ser comprendida y encarada de una manera integral. Es una violación múltiple y continuada de numerosos derechos reconocidos en la Convención, que los Estados Partes están obligados a respetar y garantizar».

En este mismo tenor se expresó en Blake vs. Guatemala (1998), donde se señala que «la Corte ha dicho en otros casos de desaparición forzada de personas que ésta constituye una violación múltiple y continuada de varios derechos protegidos por la Convención». Y en 19 comerciantes vs. Colombia (2004), volvió a definir a la DFP como «un hecho ilícito que genera una violación múltiple y continuada de varios derechos protegidos por la Convención». Nótese que en los precedentes enunciados no sólo se ha establecido la característica pluriofensiva del delito de DFP, sino que también se ha señalado su carácter continuo o permanente; toda vez que, seguido del término "múltiple", se ha agregado la expresión "continuada".

Por tanto, un segundo estándar interpretativo sustancial que ha establecido la $\mathrm{CIDH}$, es el relativo al carácter permanente que debe atribuirse al delito de DFP. Tal criterio es crucial para que los autores de dicho crimen no alcancen la impunidad mediante la aplicación de cualquier tipo de amnistía o prescripción. El concepto de delito permanente, que la CIDH le otorga a la DFP, implica que es una conducta ilícita que se prolonga indefinidamente en el tiempo, hasta tanto no se halle a la víctima objeto del crimen. Así, en Blake vs. Guatemala (Excepciones Preliminares) de 1996, la Corte incluyó como nuevas fuentes aplicables en materia de DFP, a la Declaración de la ONU de 1992 y a la CIDFP, al sostener que la mencionada

\footnotetext{
${ }^{8}$ Como se sabe, la CADH garantiza el libre y pleno ejercicio de los derechos y libertad a toda persona «sin discriminación alguna por motivos de raza, color, sexo, idioma, religión, opiniones políticas o de cualquier otra índole, origen nacional o social, posición económica, nacimiento o cualquier otra condición social» (art. 1.1), añadiendo que «para los efectos de esta Convención, persona es todo ser humano» (art. 1.2).
} 
Declaración afirma que «todo acto de desaparición forzosa será considerado delito permanente mientras sus autores continúen ocultando la suerte y el paradero de la persona desaparecida y mientras no se hayan esclarecido los hechos» (art. 17.1). También la CIDFP se expresa en el mismo sentido:

«Los Estados Partes se comprometen a adoptar, con arreglo a sus procedimientos constitucionales, las medidas legislativas que fueren necesarias para tipificar como delito la desaparición forzada de personas, y a imponerle una pena apropiada que tenga en cuenta su extrema gravedad. Dicho delito será considerado como continuado o permanente mientras no se establezca el destino o paradero de la víctima» (art. 3).

La CIDH, basándose en dichos principios de derecho internacional, confirmó que:

«La desaparición forzada implica la violación de varios derechos reconocidos en los tratados internacionales de derechos humanos (...), y que los efectos de estas infracciones (...), pueden prolongarse de manera continua o permanente hasta el momento en que se establezca el destino o paradero de la víctima» (Blake vs. Guatemala, Excepciones Preliminares § 39).

El carácter permanente de la DFP presenta algunas ventajas: la primera, es que evita cualquier tipo de prescripción o amnistía del delito; la segunda, es que garantiza la validez temporal de la normativa aplicable al caso concreto; y la tercera, es que justifica la competencia de la CIDH.

La CIDH ratificaría el carácter de delito permanente de la DFP en Goiburú y otros vs. Paraguay (2006, § 83), en donde reconoce que las disposiciones de los distintos tratados internacionales en la materia, obligan a «considerar integralmente el delito de desaparición forzada en forma autónoma y con carácter continuado o permanente, con sus múltiples elementos complejamente interconectados y hechos delictivos conexos». Dos años más tarde, la Corte arribaría a la misma conclusión en Heliodoro Portugal vs. Panamá (2008, § 34), donde señala que:

«La desaparición forzada de personas se caracteriza por ser una violación de carácter continuo o permanente. Lo anterior permite que la CIDH pueda pronunciarse sobre una presunta desaparición forzada, aún si ésta se inicia con anterioridad a la fecha en que el Estado reconoce la competencia de la Corte, siempre y cuando dicha violación permanezca o continúe con posterioridad a dicha fecha».

La misma postura adoptó en el caso Radilla Pacheco vs. México $(2009, \S 23)$ : «Dentro de esta categoría de actos se encuentra la desaparición forzada de personas, cuyo carácter continúo o permanente ha sido reconocido de manera reiterada por el Derecho Internacional de los 
Derechos Humanos». Como se observa, el delito de DFP se inicia con la privación de la libertad, y luego se continúa cometiendo a lo largo del tiempo, hasta tanto no se halle a la persona o sus restos, o se esclarezcan los hechos y su situación de desaparecida. En este punto, resulta pertinente aclarar que la mera presunción de que un cadáver pueda pertenecer a un individuo desaparecido, no basta para hacer cesar la conducta delictiva. Así lo dispuso la CIDH en Ibsen Cárdenas e Ibsen Peña vs. Bolivia (2010, § 82):

«En casos de presunta desaparición forzada en que existan indicios de que la alegada víctima ha fallecido, la determinación de si se ha configurado dicho fenómeno y la cesación del mismo, en su caso, implica, necesariamente, establecer de la manera más fehaciente la identidad del individuo a quien pertenecen los restos recolectados».

La tercera regla significativa que la $\mathrm{CIDH}$ ha establecido sobre el delito de DFP, consiste en la determinación de sus elementos constitutivos, es decir, la descripción de los supuestos que tienen que producirse para que dicha conducta penal se materialice. En éste sentido, en Chitay Nech y otros vs. Guatemala (2010, § 85), la Corte indicó que tanto la Declaración de la ONU de 1992, como la CIDFP y el Estatuto de Roma, coinciden en señalar que los elementos concurrentes y constitutivos de la DFP son: «a) la privación de la libertad; b) la intervención directa de agentes estatales o la aquiescencia de éstos, y c) la negativa de reconocer la detención o de revelar la suerte o paradero de la persona interesada».

De la citada enumeración puede extraerse que el delito contra el derecho a la vida, es decir la muerte de la víctima, no es una conditio sine qua non para que la DFP se consume; por el contrario, basta, solamente, que los tres presupuestos citados por la CIDH se produzcan de manera concomitante. Tal criterio se reiteró en los siguientes fallos: Gomes Lund y otros ("Guerrilla do Araguaia") vs. Brasil (2010, § 104), Gudiel Álvarez y otros ("Diario Militar") vs. Guatemala (2012, § 193) y Rodríguez Vera y otros (Desaparecidos del Palacio de Justicia) vs. Colombia (2014, § 366), donde la Corte, además de confirmar su posición sobre los elementos que integran la DFP, indicó que éstos son útiles para diferenciar una DFP de una ejecución extrajudicial:

«Una de las características de la desaparición forzada, a diferencia de la ejecución extrajudicial, es que conlleva la negativa del Estado de reconocer que la víctima está bajo su control y de proporcionar información al respecto, con el propósito de generar incertidumbre acerca de su paradero, vida o muerte, de provocar intimidación y supresión de derechos» (Rodríguez Vera et al. vs. Colombia, $\S 366)$. 
Por otro lado, en el caso Gómez Palomino vs. Perú (2005, § 103), la misma Corte declaró que la negativa del Estado de reconocer la detención y revelar la suerte o el paradero de la persona detenida, es un elemento que necesariamente «debe estar presente en la tipificación del delito, porque ello permite distinguirlo de otros con los que usualmente se la relaciona, como el plagio o secuestro y homicidio».

Dos últimas conclusiones se desprenden del análisis de los elementos constitutivos que para la Corte integran el crimen de DFP. La primera, es el hecho de que el sujeto activo del delito es el Estado, en cualquiera de sus formas. Por tanto, la responsabilidad estatal se mantiene, incluso, en el supuesto de que un particular, que haya actuado con el apoyo o aquiescencia del Estado, cometa una DFP. Por ello, la CIDH sostiene que «la sanción penal debe alcanzar a todas las personas que realicen conductas constitutivas de desaparición forzada» (Gomes Palomino vs. Perú, 2005, § 100). La segunda conclusión está enfocada en la privación de la libertad. Sobre el particular la $\mathrm{CIDH}$ ha dicho que «resulta indistinta la manera que adquiere la privación de la libertad a los fines de la caracterización de una desaparición forzada» (Osorio Rivera vs. Perú, 2013, § 125); por tanto, la privación de la libertad puede ser legal o ilegal, sin que ello afecte la tipificación del delito, ya que lo que importa es que, al menos inicialmente, se produzca una privación al derecho de la libertad personal. Para clarificar dicha posición, el Grupo de Trabajo sobre las Desapariciones Forzosas e Involuntarias de Personas de la ONU $(2008, \S 7)$ ha aclarado que:

«La desaparición forzada puede iniciarse con una detención ilegal o con un arresto o detención inicialmente legal. Es decir que la protección de la víctima contra la desaparición forzada debe resultar efectiva contra la privación de la libertad, cualquiera sea la forma que ésta revista, y no limitarse a los casos de privación ilegal de la libertad» (el documento ha sido citado repetidas veces por la CIDH).

Un cuarto estándar interpretativo a destacar es el atinente a la carga de la prueba. La CIDH ha dispuesto que la carga de la prueba, en materia de DFP, debe recaer sobre el Estado demandado; toda vez que es éste quien detenta el control de los medios para aclarar los hechos ocurridos bajo su jurisdicción. La jurisprudencia de la CIDH ha establecido, ya, desde sus albores, que «la carga de la prueba en materia de recursos internos le corresponde al Gobierno» (Velásquez Rodríguez vs. Honduras); y en Neira Alegría y otros vs. Perú (1995) la misma Corte declaró la responsabilidad internacional del Estado peruano por la DFP de tres internos durante un operativo militar realizado en el establecimiento penal "El Frontón", durante los días 18 y 19 de junio de 1986: 
La Corte considera que no corresponde a la Comisión demostrar el paradero de las tres personas a que se refiere este proceso, sino que, por la circunstancia de que en su momento los penales y luego las investigaciones estuvieron bajo el control exclusivo del gobierno, la carga de la prueba recae sobre el Estado demandado.

Un quinto criterio jurisprudencial preeminente en cuestión de DFP, es la denominada competencia ratione temporis de la CIDH para intervenir en casos de DFP. En Heliodoro Portugal vs. Panamá, el máximo tribunal interamericano de justicia, entendió que para determinar el alcance de su competencia debe ceñirse al principio de irretroactividad de los tratados internacionales, consagrado en el art. 28 de la Convención de Viena sobre el Derecho de los Tratados (1969). Al aplicar dicha solución, la CIDH asume que no puede ejercer su competencia para «Aplicar la Convención y declarar una violación a sus normas cuando los hechos alegados o la conducta del Estado demandado que pudiera implicar responsabilidad internacional son anteriores al reconocimiento de dicha competencia» (Heliodoro Portugal vs. Panamá, 2008, §24). Sin embargo, la CIDH se encuentra habilitada para ejercer su competencia ratione temporis en circunstancias fácticas que versen sobre la comisión de delitos permanentes, que impliquen una violación continua de los derechos reconocidos en la Convención, como es el caso de la DFP, es decir: «Aquellas que tuvieron lugar antes de la fecha de reconocimiento de la competencia de la Corte y persisten aún después de esa fecha» (Heliodoro Portugal vs. Panamá, 2008). Una particularidad que debe señalarse aquí, es que si la víctima de DFP sufrió, además, de manera concomitante, una ejecución extrajudicial, es decir, una violación clara contra su derecho a la vida, y la misma hubiese acontecido con anterioridad a la fecha en la que el Estado demandado se obligó a reconocer la competencia de la CIDH, ese delito, esa ejecución extrajudicial, no podrá ser analizada por el tribunal, ya que éste carece de competencia para pronunciarse sobre dicho supuesto, en virtud del principio de irretroactividad de los tratados internacionales. No obstante, sí tendrá competencia para intervenir en una DFP, debido al carácter permanente o continuo de la misma:

A diferencia de las ejecuciones extrajudiciales, la desaparición forzada de personas se caracteriza por ser una violación de carácter continuo o permanente. Lo anterior permite que la Corte pueda pronunciarse sobre una presunta desaparición forzada, aún si esta se inicia con anterioridad a la fecha en que el Estado reconoce la competencia de la Corte, siempre y cuando dicha violación permanezca o continúe con posterioridad a dicha fecha (Heliodoro Portugal vs. Panamá, 2008, § 34).

Finalmente, un sexto y último estándar interpretativo a destacar, es el vinculado al modo en que la CIDH ordena la reparación del daño ocasionado 
por la DFP. Aquí es importante diferenciar, por un lado, las reparaciones de carácter pecuniario; y por el otro, las medidas de satisfacción y garantías de no repetición aplicadas al Estado condenado. La reparación monetaria es impuesta por la CIDH para reparar el daño material e inmaterial producido por la DFP. El daño material puede subdividirse en daño emergente y en pérdida de ingresos. El daño emergente, básicamente, consiste en los gastos que ha demandado para la familia del desaparecido, la búsqueda de su paradero, así lo ha dispuesto la CIDH en Radilla Pacheco vs. México (2009, $\S 368)$ y en Chitay Nech y otros vs. Guatemala (2010, § 265). Mientras que la pérdida de ingresos debe calcularse en virtud del llamado «lucro cesante», es decir, los ingresos que habría percibido la víctima hasta su posible fallecimiento natural; así se ha establecido en Velásquez Rodríguez vs. Honduras (1989, § 46), y en Anzualdo Castro vs. Perú (2009, § 213).

En lo atinente al daño inmaterial, éste se divide en el daño sufrido por la víctima desaparecida y en el daño sufrido por sus familiares. El daño inmaterial infringido a la víctima resulta, según la $\mathrm{CIDH}$, de la angustia y el terror que la persona experimenta ante la desaparición forzosa (Goiburú y otros vs. Paraguay, 2006, § 157). Una característica de este tipo de lesiones es que no requiere pruebas. Por su parte, el daño inmaterial que sufren los familiares de la víctima es una extensión del daño ocasionado a la víctima; cabe deducir la ruptura del trato afectuoso con los miembros de la familia durante la desaparición, que tampoco es necesario demostrar (Goiburú y otros vs. Paraguay, 2006, § 159).

En cuanto a las medidas de satisfacción y garantías de no repetición que la CIDH impone a los Estados condenados, podemos mencionar: (i) La búsqueda, identificación y sepultura de restos mortales de detenidos desaparecidos: ya que conocer el paradero de la persona desaparecida es un acto de justicia que dignifica a la víctima, al darle una apropiada sepultura. (19 Comerciantes vs. Colombia, 2004, § 266). (ii) El tratamiento físico y psicológico para los familiares de la víctima: el Estado tiene la obligación de brindar atención médica, psicológica o psiquiátrica gratuita e inmediata a los familiares de las víctimas de DFP, valiéndose de instituciones estatales especializadas, y si el Estado careciera de dichas instituciones, deberá recurrir a instituciones privadas especializadas (Gomes Lund y otros (Guerrilha do Araguaia vs. Brasil, 2010, §§ 267-268). (iii) La realización de actos o monumentos que preserven la memoria: es necesario que el Estado construya monumentos para recordar a las víctimas desaparecidas, a los fines de generar conciencia sobre las aberraciones de tales crímenes, lo cual servirá para evitar que dichos delitos vuelvan a ocurrir en el futuro (19 Comerciantes vs. Colombia, 2004, § 273). (iv) La creación de sistemas de información genética, para recolectar y clasificar datos que ayuden a 
esclarecer la identidad y filiación de personas desaparecidas (Hermanas Serrano Cruz vs. El Salvador, 2005, §§ 192 y 193). (v) La educación en derechos humanos para funcionarios públicos, a fin de evitar futuras repeticiones de crímenes (Goiburú y otros vs. Paraguay, 2006, § 178). (vi) acceso público a los archivos estatales, para lograr la transparencia de los datos gubernamentales relativos a este delito; esto favorecerá el curso de las investigaciones judiciales y evitará obstaculizar el accionar de la justicia (Gelman vs. Uruguay, 2011, § 282).

\section{IMPACTO RECIENTE DE LAS SENTENCIAS DE LA CIDH SOBRE DESAPARICIÓN FORZADA DE PERSONAS}

La competencia de la Corte para intervenir en causas que versen sobre violaciones a los derechos humanos, cometidas por los Estados signatarios de la $\mathrm{CADH}$, encuentra su fundamento en el art. 33 de la citada convención. En virtud del artículo, la CIDH se encuentra facultada para determinar la responsabilidad internacional de un Estado demandado por la presunta comisión del delito de DFP, además de dar seguimiento a la ejecución de sus sentencias, así lo establece el art. 65: «de manera especial y con las recomendaciones pertinentes, señalará los casos en que un Estado no haya dado cumplimiento a sus fallos».

Reseñamos a continuación las repercusiones más recientes generadas por fallos de la CIDH en la materia. Así, el pasado 17 de noviembre de 2017, México aprobó la llamada "Ley General en Materia de Desaparición Forzada de Personas, Desaparición cometida por Particulares y del Sistema Nacional de Búsquedas de Personas", ley que es consecuencia de lo dispuesto por la CIDH en Radilla Pacheco vs. México (2009). En el fallo el tribunal indicó que el Estado mexicano debía llevar a cabo las reformas legislativas para compatibilizar su derecho interno con los estándares internacionales en materia de DFP. En concreto, la decisión observó que el art. 215 del Código Penal Federal de México debía reformarse:

«El Estado no ha cumplido plenamente las obligaciones que le impone el artículo 2 de la Convención Americana, en relación con los artículos I y III de la CIDFP, para garantizar debidamente la investigación y eventual sanción de los hechos constitutivos de desaparición forzada en el presente caso».

No cumplía fundamentalmente porque el art. 215 circunscribía el sujeto activo del delito a servidores públicos, ignorando lo consagrado en el art. 1, inciso b) de la CIDFP, que señalaba que la sanción por DFP debe alcanzar a todos los autores, cómplices y encubridores, ya sean agentes del 
Estado o personas que hayan actuado con apoyo directo o indirecto de éste. Por otro lado, el artículo tampoco tipificaba la negativa a reconocer la privación de la libertad o a dar información sobre el paradero de la víctima, como elemento constitutivo de la DFP. Por lo tanto, a partir de la sentencia de la CIDH, México inició una reforma legislativa que culminó con la sanción de la mencionada Ley, la cual, según la Comisión (1-XII-2017), responde a los estándares internacionales sobre derechos humanos.

Una segunda repercusión relevante causada por una sentencia de la CIDH se produjo a fines de 2016, cuando Panamá modificó la tipificación del delito de DFP en el art. 152 del Código Penal. Ello se hizo en cumplimiento de la sentencia del caso Heliodoro Portugal vs. Panamá, donde se determinó que el Estado había incumplido la obligación de tipificar el delito de DFP en su derecho interno, conforme lo establece el art. 2 de la CADH. Debido a esta ausencia de tipificación, el crimen de Heliodoro Portugal fue investigado bajo el tipo penal de homicidio y la errónea calificación legal implicó el desconocimiento de la característica pluriofensiva y permanente de la DFP, ya que el homicidio sólo lesiona el derecho a la vida y su acción penal es susceptible de prescripción. Por ello, la CIDH conminó a Panamá a adecuar su legislación interna conforme a los principios convencionales. De aquí rescatamos que la DFP debe gozar de una categoría autónoma, pluriofensiva y permanente, para que su conducta penal no pueda quedar reducida, subsumida o desvirtuada por otro delito; ya sea el secuestro, la tortura o el homicidio. También resulta necesario que los Estados describan expresamente las conductas punibles que lo componen, en sus respectivos códigos penales; es decir, la privación de la libertad, con apoyo o aquiescencia del Estado de manera directa o indirecta, seguida por la falta de información o negativa a reconocer la privación o informar sobre el paradero de la persona desaparecida. En el mismo sentido, deben manifestar el carácter permanente que posee el delito, siendo por ello, de acción penal imprescriptible.

Una tercera consecuencia relevante producida por un fallo de la CIDH, fue la inclusión del delito de DFP en el Código Penal argentino. Aunque la tipificación no surgió por disposición directa de la CIDH, sí fue una consecuencia colateral del proceso judicial, ya que la Ley 26. 679 que modificó el Código Penal ${ }^{9}$ fue sancionada por el Congreso Nacional el 13

\footnotetext{
${ }^{9}$ La ley 26.679, incorporó el art. 142 ter al Código Penal que cumple con los elementos constitutivos de la DFP. El artículo impone prisión «al funcionario público o a la persona o miembro de un grupo de personas que, actuando con la autorización, el apoyo o la aquiescencia del Estado, de cualquier forma, privare de la libertad a una o más personas, cuando este accionar fuera seguido de la falta de información o de la negativa a reconocer dicha privación de libertad o de informar sobre el paradero de la persona».
} 
de abril de 2011, es decir, sólo cuatro meses antes de que la CIDH estableciera la responsabilidad internacional de Argentina por la desaparición forzada de Iván Eladio Torres Millacura (cfr. Torres Millacura y Otros vs. Argentina, 2011). En el caso, la CIDH no obligó a adoptar disposiciones de derecho interno que estén en consonancia con la CADH y con la CIDFP, porque:

«La Comisión Interamericana no alegó que la falta de tipificación del delito de desaparición forzada de personas haya constituido un impedimento u obstáculo para la investigación de lo sucedido al señor Torres. Por lo tanto, la Corte no puede pronunciarse en abstracto sobre este punto».

Por lo expuesto hasta aquí, podemos afirmar que uno de los mayores logros recientes que ha tenido la CIDH en materia de DFP, es su capacidad para compeler a los Estados miembros de la OEA, que han aceptado su jurisdicción, a que realicen reformas legislativas sustanciales para erradicar la abominable práctica de la DFP.

\section{CONCLUSIón}

De lo desarrollado hasta aquí, arribamos a las siguientes conclusiones:

1. El delito de DFP tiene su origen, a nivel mundial, en las Directivas para la persecución de las infracciones cometidas contra el Reich o las Fuerzas de Ocupación en los Territorios Ocupados (1941), conocidas luego de los Juicios de Núremberg con el nombre de «Decreto Noche y niebla» redactado por el mariscal Wilhelm Keitiel y ordenado por Adolf Hitler, durante el comienzo de la Segunda Guerra Mundial.

2. En América Latina este delito comenzó a practicarse en Guatemala, en el año 1966, con el tristemente célebre caso de los 28 desaparecidos, ocurrido durante el Gobierno de facto de Enrique Peralta Azurdia. A partir de allí, el mentado crimen se propagaría al resto de América Latina, encontrando su versión más siniestra y sistemática, en las dictaduras latinoamericanas de la década del setenta, en las que el fenómeno se perfeccionó con grupos de tareas especializados en evaporar a las personas.

3. Por DFP debe entenderse todo delito de lesa humanidad, imprescriptible, consistente en la privación de la libertad de una o más personas, mediante arresto, detención, traslado o cualquier otro medio,

Simultáneamente, en el art. 215 bis al Código Penal incluyó el carácter permanente del delito de DFP. Al respecto señala que no el Juez no podrá disponer el archivo de las causas en que se investiguen casos de DFP «hasta tanto la persona no sea hallada o restituida su identidad». Igual impedimento rige para el Ministerio Público Fiscal. 
perpetrado por agentes estatales, por particulares al servicio de éste, o por organizaciones políticas; quienes proceden a ocultar a la persona, para luego negar o desconocer cualquier información relativa al paradero, ubicación o destino de la víctima, con el fin, claro y deliberado, de sustraerla de la protección jurídica correspondiente.

4. Una de las más poderosas herramientas con las que cuenta la justicia internacional es la CIDH, que tiene la potestad para obligar a los Estados miembros que han reconocido su jurisdicción, a que cumplan con su deber de esclarecer las DFP que suceden o han sucedido en sus territorios.

5. Por todo lo expuesto se concluye que, la DFP, representa uno de los delitos más perversos que puedan cometerse contra la humanidad, no sólo por las diversas torturas y tormentos a los que, generalmente, la víctima es sometida; sino porque su finalidad es la de crear un limbo jurídico en el que la persona quede completamente despojada de toda protección legal. Los delitos de DFP no deben olvidarse jamás, ya que su investigación y esclarecimiento suponen mantener viva la llama de la más elemental dignidad humana. 


\section{REFERENCIAS}

Abuelas de Plaza de Mayo (2016). Son 30 mil. En https://www.abuelas.org.ar/noticia/sonmil-725 (recuperado el 25-II-2018).

Ambos, K., \& Böhm, M. (2009). La desaparición forzada de personas como tipo penal autónomo. Desaparición Forzada de Personas. Análisis Comparado e Internacional. 195-251. Bogotá: Editorial Temis S. A.

Amnistía Internacional (2016). Declaración pública. Bolivia: es urgente la creación de una Comisión de la Verdad para avanzar en el esclarecimiento de las violaciones de derechos humanos del pasado. En https://www.amnesty.org/es/documents /amr18/3234/2016/es/ (recuperado el 26-II-2018).

Argentina, Poder Ejecutivo. (1983). Decreto 158/83.

Ball, P., Kobrak, P., \& Spirer, H. F. (1999). Violencia Institucional en Guatemala, 19601966: una reflexión cuantitativa. Washington, DC: Centro Internacional para Investigaciones en Derechos Humanos. En http://memoriavirtualguatemala.org/node/5821 (recuperado el 26-II-2018).

Boronat, N. (2013). Testigos que desaparecen en la noche y se desvanecen en la niebla: Resnais y la memoria del Holocausto. Sesión no numerada: Revista de letras y ficción audiovisual, 3, 226-246.

Brijalbo, M. \& Londoño, C. (2004). Análisis del delito de desaparición forzada. Tesis de grado. Bogotá: Universidad Javeriana. En http://www.javeriana.edu.co/biblos /tesis/derecho/dere6/DEFINITIVA/TESIS55.pdf (recuperado el 28-II-2018).

Cámara de Diputados de la Provincia de Buenos Aires (2017). Ley 14.910.

Cámara Nacional de Apelaciones en lo Criminal y Correccional Federal de la Capital Federal. Causa 13/84. Sentencia de 9-XII-1985. En http://www.derechos.org /nizkor/arg/causa13/index.html (recuperado el 26-II-2018).

Citroni, G. (2003). Desaparición forzada de personas: desarrollo del fenómeno y respuestas de la Corte Interamericana de Derechos Humanos. Anuario de Derecho Internacional, XIX, 373-408.

Comisión Interamericana de Derechos Humanos (1972). Informe Anual 1972.

Comisión Interamericana de Derechos Humanos (1974). Informe Anual 1974.

Comisión Interamericana de Derechos Humanos (1976). Informe Anual 1976.

Comisión Interamericana de Derechos Humanos (1977). Informe Anual 1977.

Comisión Interamericana de Derechos Humanos (2017). CIDH saluda entrada en vigor de la Ley General sobre desaparición de personas en México. Washington, D.C. 1 de diciembre. En http://www.oas.org/es/cidh/prensa/comunicados/2017/196.asp (recuperado el 27-II-2018).

Congreso de la Nación Argentina. (2011). Ley 26.679. 
Congreso General de los Estados Unidos Mexicanos (2017). Ley General en Materia de Desaparición Forzada de Personas, Desaparición cometida por Particulares y del Sistema Nacional de Búsquedas de Personas. Nueva Ley DOF 17-XI-2017.

Convención Americana sobre Derechos Humanos (1969).

Convención de Viena sobre el Derecho de los Tratados (1969).

Convención Interamericana sobre Desaparición Forzada de Personas (1994).

Convención Internacional para la protección de todas las personas contra las desapariciones forzadas (2006).

Convención sobre Imprescriptibilidad de los Crímenes de Guerra y de los Crímenes de Lesa Humanidad (1968).

Corte Interamericana de Derechos Humanos. Caso Anzualdo Castro vs. Perú. Sentencia de 22-IX-2009. En http://www.corteidh.or.cr/CF/jurisprudencia2/ficha_tecnica. cfm?nId_Ficha=279 (recuperado el 27-II-2018).

Corte Interamericana de Derechos Humanos. Caso Blake vs. Guatemala (Excepciones Preliminares). Sentencia de 2-VII-1996. En www.corteidh.or.cr/docs/casos/ articulos/seriec_27_esp.pdf (recuperado el 27-II-2018).

Corte Interamericana de Derechos Humanos. Caso Blake vs. Guatemala. Sentencia de 24I-1998. En http://www.corteidh.or.cr/cf/Jurisprudencia2/ficha_tecnica.cfm?nId_ Ficha $=317 \&$ lang=e (recuperado el 27-II-2018).

Corte Interamericana de Derechos Humanos. Caso Chitay Nech y otros vs. Guatemala. Sentencia de 25-V-2010. En http://www.corteidh.or.cr/cf/Jurisprudencia2 /ficha_tecnica.cfm?nId_Ficha=362\&lang=e (recuperado el 27-II-2018).

Corte Interamericana de Derechos Humanos. Caso Comunidad Campesina de Santa Bárbara vs. Perú. Sentencia de 1-IX-2015. En http://www.corteidh.or.cr/cf /jurisprudencia2/ver_expediente.cfm?nId_expediente=217\&lang=es (recuperado el 24-II-2018).

Corte Interamericana de Derechos Humanos. Caso de las Hermanas Serrano Cruz vs. El Salvador. Sentencia de 1-III-2005. En http://www.corteidh.or.cr/cf/Jurispru dencia2/ficha_tecnica.cfm?nId_Ficha=247\&lang=e (recuperado el 27-II-2018).

Corte Interamericana de Derechos Humanos. Caso de los 19 comerciantes vs. Colombia. Sentencia de 5-VII-2004. En http://www.corteidh.or.cr/cf/Jurisprudencia2 /ficha_tecnica.cfm?nId_Ficha=274\&lang=e (recuperado el 27-II-2018).

Corte Interamericana de Derechos Humanos. Caso Fairén Garbi y Solís Corrales vs. Honduras. Sentencia de 15-III-1989. En http://www.corteidh.or.cr/cf/Jurisprud encia2/ficha_tecnica.cfm?nId_Ficha=190\&lang=e (recuperado el 26-II-2018).

Corte Interamericana de Derechos Humanos. Caso Gelman vs. Uruguay. Sentencia de 24II-2011. En http://www.corteidh.or.cr/cf/Jurisprudencia2/ficha_tecnica.cfm?nId _Ficha=345\&lang=e (recuperado el 27-II-2018).

Corte Interamericana de Derechos Humanos. Caso Godinez Cruz vs. Honduras. Sentencia de 20-I-1989. En http://www.corteidh.or.cr/cf/Jurisprudencia2/ficha_tecnica .cfm?nId_Ficha=194\&lang=e (recuperado el 26-II-2018). 
Corte Interamericana de Derechos Humanos. Caso Goiburú y otros vs. Paraguay. Sentencia de 22-IX-2006. En http://www.corteidh.or.cr/cf/jurisprudencia2/ficha_tecnica. cfm?nId_Ficha=387\&lang=es (recuperado el 27-II-2018).

Corte Interamericana de Derechos Humanos. Caso Gomes Lund y otros ("Guerrilla do Araguaia”) vs. Brasil Sentencia de 24-XI-2010. En http://www.corteidh.or.cr/ cf/Jurisprudencia2/ficha_tecnica.cfm?nId_Ficha=342\&lang=e (recuperado el 27-II-2018).

Corte Interamericana de Derechos Humanos. Caso Gómez Palomino vs. Perú. Sentencia de 22-XI-2005. En http://www.corteidh.or.cr/cf/Jurisprudencia2/ficha_tecnica. cfm?nId_Ficha=314\&lang=e (recuperado el 27-II-2018).

Corte Interamericana de Derechos Humanos. Caso Gudiel Álvarez y otros ("Diario Militar”) vs. Guatemala. Sentencia de 20-XI-2012. En http://www.corteidh.or.cr /CF/jurisprudencia2/ficha_tecnica.cfm?nId_Ficha=231 (recuperado el 27-II2018).

Corte Interamericana de Derechos Humanos. Caso Heliodoro Portugal vs. Panamá. Sentencia de 12-VIII-2008. En http://www.corteidh.or.cr/CF/jurisprudencia2 /ficha_tecnica.cfm?nId_Ficha=307 (recuperado el 27-II-2018).

Corte Interamericana de Derechos Humanos. Caso Ibsen Cárdenas e Ibsen Peña vs. Bolivia. Sentencia de 1-IX-2010. En http://www.corteidh.or.cr/cf/Jurisprudencia2 /ficha_tecnica.cfm?nId_Ficha=340\&lang=e (recuperado el 26-II-2018).

Corte Interamericana de Derechos Humanos. Caso Neira Alegría y otros vs. Perú. Sentencia de 19-I-1995. En http://www.corteidh.or.cr/CF/jurisprudencia2/ficha_tecnica .cfm?nId_Ficha=219 (recuperado el 27-II-2018).

Corte Interamericana de Derechos Humanos. Caso Osorio Rivera vs. Perú. Sentencia de 26-XI-2013. En http://www.corteidh.or.cr/cf/Jurisprudencia2/ficha_tecnica. cfm?nId_Ficha=368\&lang=e (recuperado el 27-II-2018).

Corte Interamericana de Derechos Humanos. Caso Radilla Pacheco vs. México. Sentencia de 23-XI-2009. En http://www.corteidh.or.cr/cf/Jurisprudencia2/ficha_tecnica .cfm?nId_Ficha=360\&lang=e (recuperado el 24-II-2018).

Corte Interamericana de Derechos Humanos. Caso Rodríguez Vera y otros (Desaparecidos del Palacio de Justicia) vs. Colombia. Sentencia de 14-XI-2014. En http://www.corteidh.or.cr/cf/jurisprudencia2/ver_expediente.cfm?lang=es\&nId _expediente=193 (recuperado el 27-II-2018).

Corte Interamericana de Derechos Humanos. Caso Torres Millacura y otros vs. Argentina. Sentencia de 1-VIII-2011. En http://www.corteidh.or.cr/CF/jurisprudencia 2/ficha_tecnica.cfm?nId_Ficha=351 (recuperado el 24-II-2018).

Corte Interamericana de Derechos Humanos. Caso Velásquez Rodríguez vs. Honduras. Sentencia de 29-VII-1988. En http://www.corteidh.or.cr/cf/jurisprudencia2 /ficha_tecnica.cfm?lang=es\&nId_Ficha=189 (recuperado el 25-II-2018).

Corte Interamericana de Derechos Humanos. Caso Vereda La Esperanza vs. Colombia. Sentencia de 31-VIII-2017. En http://www.corteidh.or.cr/CF/Jurisprudencia2 /busqueda_casos_contenciosos.cfm (recuperado el 24-II-2018). 
Corte Penal Internacional (1998). Estatuto de Roma.

Corte Suprema de Justicia de Chile (2004). Sentencia de la Segunda Sala Excma. Corte Suprema. Rol 517-2004. Revista Ius et Praxis, 10(2), 337-375.

Dallari, P. (2015). La Comisión Nacional de la Verdad de Brasil: algunas notas sobre su trabajo, informe final, conclusiones y recomendaciones con un enfoque en el sistema de justicia. Revista Sistemas Judiciales, 19, 46-54.

Declaración sobre la protección de todas las personas contra las desapariciones forzadas (1992).

Diario El País. (30-X-1979). Juan Pablo II denuncia las “desapariciones” en Argentina y Chile. Madrid. En https://elpais.com/diario/1979/10/30/internacional/310086 020_850215.html (recuperado el 25-II-2018).

Diario Infobae. (17-V-2013). Videla y su histórica explicación sobre los desaparecidos. Buenos Aires. En https://www.infobae.com/2013/05/17/711088-videla-y-suhistorica-explicacion-los-desaparecidos/ (recuperado el 24-II-2018).

Grupo de Trabajo sobre las Desapariciones Forzadas o Involuntarias (10-I-2008). Informe del Grupo de Trabajo sobre las Desapariciones Forzadas o Involuntarias, Comentario general sobre la definición de desapariciones forzadas, A/HRC/7/2.

Huhle, R. (2014). Noche y Niebla. Mito y significado. Desapariciones forzadas de niños en Europa y Latinoamérica: del Convenio de la ONU a las búsquedas a través del ADN. IV, 251-278. Barcelona: Universitat de Barcelona. En https://dialnet.unirioja.es/servlet/libro?codigo=567694 (recuperado el 25-II2018).

Instituto Nacional de Derechos Humanos de Chile (2011). Informe de la Comisión Presidencial Asesora para la Calificación de Detenidos y Desaparecidos, Ejecutados Políticos y Víctimas de Prisión Política y Tortura. En https://www.indh.cl/destacados/comision-valech/ (recuperado el 25-II-2018).

Ministerio de Justicia y Derechos Humanos de la Nación Argentina (2016). Registro Unificado de Víctimas del Terrorismo de Estado. En http://datos.jus.gob.ar/dataset/registro-unificado-de-victimas-del-terrorismo-deestado-ruvte/archivo/c6b674bc-e178-41f3-81f5-0f10038e1688 (recuperado el 25-II-2018).

Molina Theissen, A. L. (1996). La desaparición forzada de personas en América Latina. Estudios Básicos de Derechos Humanos, VII, 65-129. En http://www.iidh.ed.cr/iidh/publicaciones/series/ (recuperado el 24-II-2018).

Organización de las Naciones Unidas (1978). Resolución 33/173.

Organización de los Estados Americanos (1983). Resolución 666 (XIII-0/83).

Pigna, F. (18-V-2013). Lo Pasado Pensado - Felipe Pigna - La Conferencia de Videla (1979). En https://www.youtube.com/watch?v=7PCzaoEPv10 (recuperado el 25-II-2018).

Simon, J.M. (2003). La Comisión para el Esclarecimiento Histórico, Verdad y Justicia en Guatemala. Boletín Mexicano de Derecho Comparado, 36(106), 148-203. 